\title{
Seroprevalence of Transfusion Transmitted Infections in a Rural Tertiary Care Hospital
}

\author{
Authors \\ Sagar Chandrakant Mhetre ${ }^{1}$, Mugdha Pradeep Kulkarni ${ }^{2}$ \\ ${ }^{1}$ Professor, Department of Pathology, Ashwini Rural Medical College, Solapur \\ ${ }^{2}$ Final MBBS student, Ashwini Rural Medical College, Solapur \\ Corresponding Author \\ Mugdha Pradeep Kulkarni
}

Blood Bank, Ashwini Rural Medical College, Hospital and Research Center, Kumbhari, Solapur

\begin{abstract}
Introduction: Transfusion of blood and blood components is life saving but it has life threatening hazards also. Transfusion transmitted infections (TTIs) continue to be a great threat to the safety of transfusions all over the world. The present study aimed at the evaluation of the prevalence and trends of various TTIs in the blood bank in rural area of Solapur district, Maharashtra, India.

Material and Methods: This was a retrospective study over a period of three years from January 2015 to December 2017. We studied the frequency, age and gender wise distribution as well as the year wise trend of seroprevalence of various TTIs in the blood donors at our blood bank.

Results: Total 21,207 blood donors of both sexes were included in the study out of which 683 (3.22\%) were seropositive. The seropositivity for Hepatitis $B$ was highest, $2.41 \%$ followed by Hepatitis $C 0.46 \%$, Syphilis $0.19 \%$, HIV $0.14 \%$ and malaria 0\%. The seropositivity in males was $98.39 \%$ and in females $1.61 \%$. Highest seropositivity was in the age group 18- 31 years. There was no case of coinfection. The study showed a declining trend for all the TTIs over the three year period.

Conclusion: Voluntary blood donations, strict donor selection and screening for TTIs are crucial for decreasing the prevalence of TTIs and thereby increasing the blood safety.

Keywords: Transmission transmitted infections, Hepatitis B, Hepatitis C, HIV.
\end{abstract}

\section{Introduction}

Human blood is very precious because despite advances in science and technology it has not been possible to synthesize blood. The demand for blood is continually increasing and currently estimated annual requirement of blood in India is 12.8 million units ${ }^{[1]}$

Transfusion transmitted infectious (TTIs) pose a great burden on transfusion services as they result in complete wastage of blood and continue to be a threat to the health of the community.With every unit of blood there is a $1 \%$ chance of transfusion associated problems including transfusion transmitted diseases ${ }^{[2]}$. Major transfusion transmitted infections in India are HIV, HBV, HCV, Syphilis and Malaria. According to World Health Organization (WHO) it is mandatory to screen for HIV, HBV, HCV, VDRL universally in 
every country ${ }^{[3]}$. The aim of this study is to determine the trend of transfusion transmitted diseases in our area.

\section{Material and Methods}

We conducted a retrospective study in blood bank of a tertiary care centre. The study was conducted over 3 years from January 2015 to December 2017 comprising of 21,207 blood donors.

The study included only voluntary blood donations. WHO guidelines were strictly followed for donor screening and blood collection ${ }^{[4]}$.

The samples were screened for HIV, HBV, HCV and Syphilis by kits provided by NACO.HIV screening was done by $3^{\text {rd }}$ generation Enzyme linked immune sorbent assay (ELISA) for detection of antibodies to HIV1 and 2.

ELISA test was also used for detection of hepatitis B surface antigen (HBsAg) and antibodies to hepatitis C.

Rapid Plasma Reagin test kit was used as a screening test for Syphilis.

For detection of malarial parasite peripheral smears prepared from donor's blood were examined.

All tests were carried out meticulously observing the standard guidelines. The serology reports were collected and analysed with reference to age and sex of the donors. The seropositive units were discarded according to the standard bio discard protocols.

\section{Results}

Our study consisted of 21,207 donors over the period of 3 years. All were voluntary donations. Total number of male donors was 20975 (98.91\%) and female donors were $232(1.09 \%)$. Total number of seropositive units was $683(3.22 \%)$ out of which $672(98.39 \%)$ were males and 11 $(1.61 \%)$ females.

Table 1 shows the frequency of seropositivity of TTIs in blood donors.HBV seropositivity was highest and significantly higher than other infections. Prevalence of syphilis was higher than that of HIV while no case of malaria was seen in our study.

Table 2 shows the age wise distribution of seropositive donors. Highest number, 408 was seen in the age group 18-31 years. This included the seropositivity for all the TTIs. Also, in every TTI, males outnumbered females as shown in table 3 .

Table 4 shows the year wise prevalence of TTIs. There was a decline in the prevalence of HBV, $\mathrm{HCV}$, Syphilis and HIV over the study period of 3 years

Table -1 Frequency of seropositivity of TTI in blood donors

\begin{tabular}{|l|c|c|c|}
\hline Sr. No & $\begin{array}{c}\text { TYPE OF } \\
\text { INFECTION }\end{array}$ & $\begin{array}{c}\text { NO OF SEROPOSITIVE } \\
\text { DONORS }\end{array}$ & $\begin{array}{c}\% \text { OF TOTAL } \\
\text { DONORS }\end{array}$ \\
\hline 1 & HBV & 512 & 2.41 \\
\hline 2 & HCV & 99 & 0.46 \\
\hline 3 & SYPHILIS & 42 & 0.19 \\
\hline 4 & HIV & 30 & 0.14 \\
\hline 5 & MALARIA & 0 & 0 \\
\hline
\end{tabular}

Table-2 Age wise distribution of TTI in blood donors

\begin{tabular}{|l|c|c|c|}
\hline Infection & $18-31$ yrs & $32-45 y r s$ & $46-60 y r s$ \\
\hline HBV & 325 & 148 & 39 \\
\hline HCV & 45 & 38 & 16 \\
\hline SYPHILIS & 20 & 19 & 3 \\
\hline HIV & 18 & 11 & 1 \\
\hline MALARIA & 0 & 0 & 0 \\
\hline TOTAL & 408 & 216 & 59 \\
\hline
\end{tabular}


TABLE-3 comparison of seropositivity between male and female blood donors

\begin{tabular}{|l|c|c|}
\hline Infection & Males & Females \\
\hline $1 . \mathrm{HBV}$ & 505 & 7 \\
\hline $2 . \mathrm{HCV}$ & 96 & 3 \\
\hline 3. SYPHILIS & 42 & 0 \\
\hline 4.HIV & 29 & 1 \\
\hline 5.MALARIA & 0 & 0 \\
\hline TOTAL & 672 & 11 \\
\hline
\end{tabular}

Table-4 Year wise distribution of TTI in blood donors

\begin{tabular}{|l|c|c|c|c|}
\hline \multirow{2}{*}{ Sr no. } & Type of TTI & \multicolumn{3}{|c|}{ NUMBER OF REACTIVE DONORS } \\
\hline & & 2015 & 2016 & 2017 \\
\hline 1 & & 210 & 173 & 129 \\
\hline 2 & HBV & 39 & 34 & 26 \\
\hline 4 & HCV & 21 & 18 & 3 \\
\hline 3 & SYPHILIS & 12 & 11 & 7 \\
\hline 5 & HIV & 0 & 0 & 0 \\
\hline & MALARIA & 282 & 236 & 165 \\
\hline
\end{tabular}

Table no. 5 Comparison of s eropositivity of blood donors in various studies

\begin{tabular}{|l|c|c|c|c|c|c|c|c|}
\hline Sr.No. & Author & Area & Year & HBV & HCV & Syphilis & HIV & Malaria \\
\hline 1 & Sulhyan et al & $\begin{array}{c}\text { Sangli,Mahara } \\
\text { shtra }\end{array}$ & $2013-17$ & 1.15 & 0.11 & 0.0 & 0.24 & $\begin{array}{c}\text { Not } \\
\text { mentioned }\end{array}$ \\
\hline 2 & NACO & India & 2015 & 0.939 & 0.326 & 0.182 & 0.136 & 0.039 \\
\hline 3 & Arya et al & North India & $2010-15$ & 1.60 & 0.18 & 0.89 & 0.10 & 0.04 \\
\hline 4 & Agrawal et al & $\begin{array}{c}\text { Southern } \\
\text { Rajasthan }\end{array}$ & $2014-16$ & 0.84 & 0.0 & 1.29 & 0.15 & 0.09 \\
\hline 5 & Present study & $\begin{array}{c}\text { Solapur, } \\
\text { Maharashtra }\end{array}$ & $2015-17$ & 2.41 & 0.46 & 0.19 & 0.14 & 0.0 \\
\hline
\end{tabular}

Caption to illustration 1: Declining Trend of Seroprevalence of TTIs

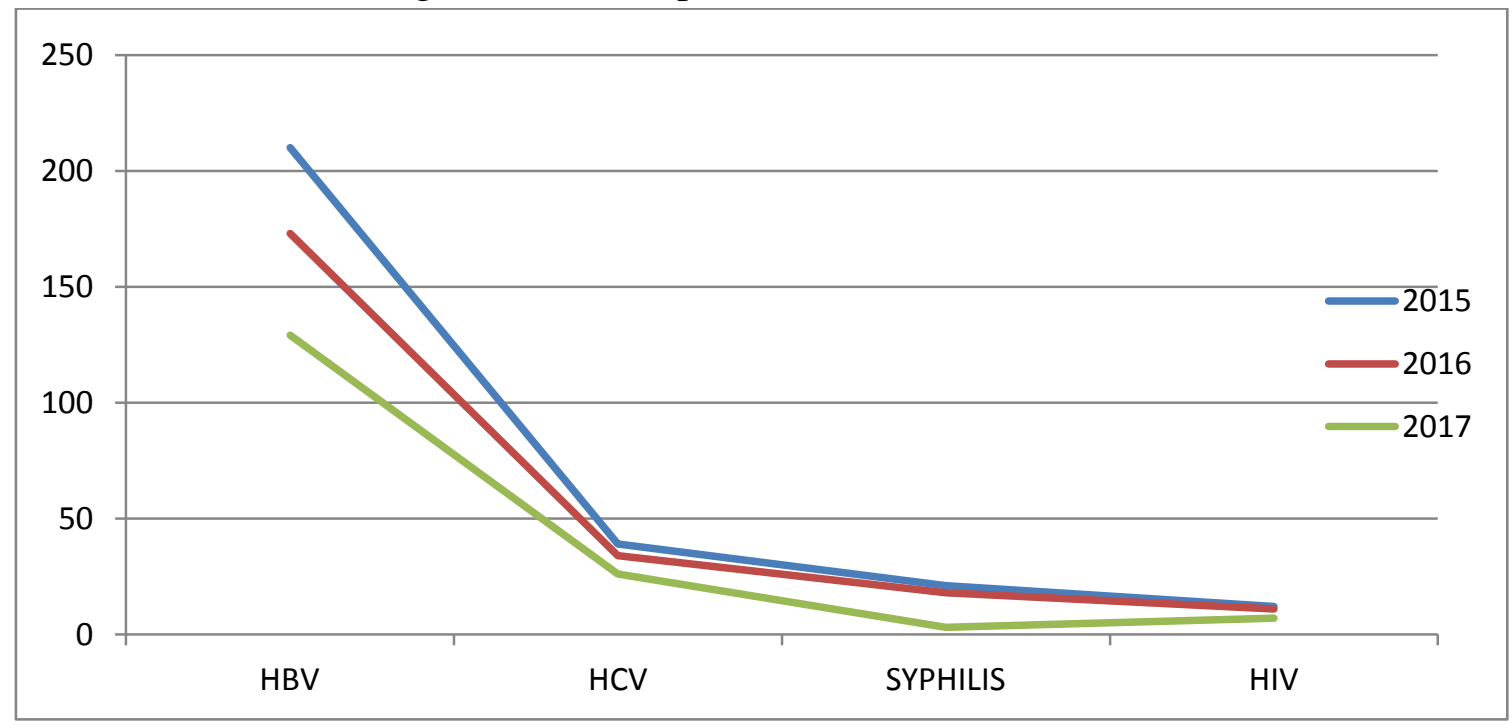

\section{Discussion}

Transfusion transmitted infections are major problems associated with blood transfusion. Although numerous bacteria and viruses can be transmitted via blood, important TTIs are HIV I and II, Hepatitis B, Hepatitis C, syphilis and malaria .Accurate estimation of risk of TTIs is essential for monitoring of blood safety and efficacy of currently employed screening programmes .Our study consisted of data over the 
period of three years including 21,207 voluntary blood donors. Majority of the donors 20,975 (98.9 $\%)$ were males and females constituted only 232 (1.09\%). In a similar study conducted by Sulhyan et al, males constituted $97.66 \%$ and females $2.33 \%$ while Fernandes et al had $97.5 \%$ males and $2.5 \%$ females in their study. ${ }^{[5,6,]}$ This gender disparity can be the result of many factors , most significant being higher prevalence of anemia in Indian women.

In the present study, the most prevalent age group was 18 - 31 years. There were 408 (59.7\%) seropositive donors from this age group. The high prevalence of infection in this sexually active age group could be due to possible high risk behaviour. Similar observation has been recorded by Sulhyan et al. ${ }^{[5]}$. The seroprevalence in males in our study was much higher $(98.39 \%)$ than in the females $(1.61 \%)$. Sulhyan et al and Makroo et al have also reported higher seroprevalence in males as compared to females ${ }^{[5,7]}$.

Table 5 shows the comparison of various studies on TTIs. In many of the studies, HBV seropositivity was highest. ${ }^{[1,5,8]}$ In our study also, HBV had highest seroprevalence for all three years accounting for total 512 donors (2.41\%).This was followed by HCV with 99 donors and prevalence of $0.46 \%$. A similar study by NACO reported highest prevalence of HBV followed by HCV among TTIs. ${ }^{[1]}$. In our study the prevalence of syphilis (42 cases, $0.19 \%$ ) was higher than that of HIV (30 cases, $0.14 \%$ ). Agrawal et al have reported highest prevalence for syphilis(1.2\%) followed by HBV, HIV, Malaria and $\mathrm{HCV}^{[9]}$. In the present study there was not a single case of malaria among the donors. This could be due to stringent donor selection criteria and also due to the consistent decline in the incidence of malaria in our country from 2001 to 2017 by the implementation of the intensified malaria control strategies ${ }^{[10]}$.We did not find a single case of coinfection in 21,207 donors probably because our study consisted only of voluntary donors and prevalence of coinfection is more in replacement donors as stated by Makroo et $\mathrm{al}^{[7]}$ Patients requiring repeated blood transfusions are more prone to acquire TTIs. As already mentioned HBV seroprevalence is highest among TTIs in many studies ${ }^{[1,5,8,]}$. The spectrum of HBV infection includes acute hepatitis, chronic hepatitis, cirrhosis and hepatocellular carcinoma .HCV is another important TTI which is the most common cause of chronic hepatitis ${ }^{[1]}$.Our study shows a steady decline in prevalence of all the TTIs from 282 in 2015 to 236 in 2016 and 165 in 2017. We feel that this is result of concerted and active efforts for blood safety.

\section{Conclusion}

The seroprevalence of HBV, HCV, HIV, Syphilis and Malaria shows a declining trend over past 3 years. Seropositivity among blood donors at our blood bank in the decreasing order is $\mathrm{HBV}$ (2.42\%), HCV (0.46\%), VDRL (0.19\%), HIV $(0.14 \%)$ and Malaria $(0 \%)$. Maximum seroprevalence is in age group 18-31.Comparison with other studies reveals regional variation in the seroprevalence. Careful donor selection and use of sensitive tests like Nucleic acid Amplification Test (NAT) will further improve blood safety and reduce TTIs.

\section{Acknowledgements}

The authors sincerely thank Mr. Shitalkumar Kumbhar and Miss Payal Jagtap for their help in data collection.

\section{Source of support: Nil \\ Conflict of Interest: Nil}

\section{References}

1. Assessment of NACO supported blood banks. A preliminary report 2016 National Aids control Organization .Available at http://naco.gov.in/sites/default/files/Assess ment $\% 20$ of $\% 20$ NACO $\% 20$ supported $\% 20$ Blood\%20Banks\%20-\%20A\%20 Preliminary\%20Report\%202016.pdf

2. Widman FK (ed) (1985) Technical manual. American Association of Blood Banks, Arlington, pp 325-344 
3. Blood Transfusion Safety .World Health Organization. Available at http://apps.who.int/iris/bitstream/10665/44 202/1/9789241547888_eng.pdf

4. Blood donor selection.World Health Organization Available at http://apps.who.int/iris/bitstream/10665/76 724/1/9789241548519_eng.pdf

5. Sulhyan KR, Anvikar AR, Ratnaparakhi AD. Seroprevalence of transfusion transmissible infections among blood donors at a tertiary care centre in Maharashtra ,India .International Journal of Contemporary Medical Research 2017;4:1865-67.

6. Fernandes H, D'souzaPF ,D'souza PM. Prevalence of transfusion transmitted infections in voluntary and replacement donors .Indian J Hematol Blood Transfus. 2010 Sep; 26(3): 89-91.

7. Makroo RL, Hegde V, Choudhari M et al. Seroprevalence of infectious markers and their trends in blood donors in a hospital based blood bank in north India. Indian J Med Res 2015;142:317-322

8. Arya DR, Mahawar NL, Pachaury R et al .Seroprevalence of transfusion transmitted infections among blood donors at a tertiary care hospital blood bank in North India .Indian j health sci 2016;9:77-81

9. Agrawal P, Jain S, Surana SS et al. Prevalence of transfusion Transmitted Infections among blood donors at a tertiary care teaching hospital in southern Rajasthan .Annals of Pathology and Laboratory Medicine,2017;4:A137-141

10. Trend of Malaria in India.National Vector Borne Diseases Control Programme Directorate of Health Services ,Ministry of Health \& Family Welfare. Available at http://nvbdcp.gov.in/malaria3.html
11. Crawford JM ,Liu C .Liver and Biliary Tract In Robbins And Cotran Pathologic Basis of Disease. Vinay Kumar, Abbas AK , Fausto N ,Aster JC (eds) $8^{\text {th }}$ edition 2010 Elsevier India. 